\title{
EL PODER DE LA ORATORIA: EL IMPACTO DEL DISCURSO DE BARACK H. OBAMA EN LA OPINIÓN PÚBLICA ${ }^{1}$
}

\author{
María LuZ ARRoYo VÁZQuez \\ UNED. Madrid \\ larroyo@flog.uned.es
}

\section{RESUMEN}

Este artículo tiene como propósito plantear la relación que existe entre los medios de comunicación y la formación de la opinión pública, poniendo como ejemplo cómo ha sido reflejado en la prensa española el impacto de la oratoria de Obama y su victoria en las elecciones estadounidenses del año 2008. En primer lugar, examinaremos el concepto de opinión pública, centrándonos en un medio de comunicación, la prensa como creadora y reflejo de opinión pública y, en segundo lugar, trataremos de ofrecer unas reflexiones sobre las grandes esperanzas que Obama ha provocado con su discurso no sólo en el electorado estadounidense sino en el mundo entero. Obama ha captado la atención mundial con un mensaje de cambio y la promesa de una nueva política, del mismo modo que hizo Franklin Delano Roosevelt con la promesa del New Deal en el año 1932, o al igual que ocurrió en 1960 cuando John Fitzgerald Kennedy fue también la opción de los que veían en Nixon la continuidad y se esforzaron por conseguir un cambio de rumbo. Se recalcará la idea de que en estos casos la victoria de los candidatos demócratas se debió, en gran medida, a un electorado que sintió la necesidad de un cambio de política. Nos centraremos, principalmente, en la mirada de la prensa española y en su repercusión sobre la imagen de Obama en la opinión pública. Finalmente, en estas páginas se hará referencia a la influencia en la oratoria de Obama de la retórica de otros presidentes que le han precedido tales como Lincoln, Franklin D. Roosevelt, y John F. Kennedy.

\footnotetext{
${ }^{1}$ Este artículo se inscribe dentro del Proyecto de Investigación HUM2006-11365/HIST, subvencionado por la Dirección General de Investigación, del Ministerio de Educación y Ciencia.
} 
Palabras Clave: opinión pública, oratoria, Obama, Lincoln, Franklin Delano Roosevelt y John F. Kennedy.

\section{ABSTRACT}

This article has the purpose to raise the relation that exits between mass media and the formation of public opinion, giving as an example the impact of Barack H. Obama's oratory and victory in 2008 US elections as it has been presented in the Spanish press. In the first part of the paper, the concept of public opinion will be examined, focusing on one mass media, the press, as a means of reflecting and creating public opinion and secondly, we will deal with the great expectations that Obama's rhetoric has provoked not only in the US electorate but also worldwide. Obama has caught the world's attention with a message of hope and the promise of a new policy in the same way as Franklin Delano Roosevelt did in 1932 with the New Deal, or as it occurred in 1960 when John F. Kennedy was also the option for the ones who saw continuity in Nixon and strived for a change. We will pinpoint that in all these cases the victory of the democrat candidates for the Presidency was largely due to an electorate that felt that a change in US politics was necessary. We will concentrate mainly on the views of Spanish press and its impact on the image of Obama in the public opinion. Finally, we will refer in these pages to the influence on Obama's oratory of the rhetoric of previous presidents such as Lincoln, Franklin D. Roosevelt, and John F. Kennedy.

KEY WoRds: public opinion, oratory, Obama, Lincoln, Franklin Delano Roosevelt and John F. Kennedy.

\section{INTRODUCCIÓN}

En este artículo, primeramente, trataremos de acercarnos brevemente al concepto opinión pública, deteniéndonos en algunas de las múltiples interpretaciones de que ha sido objeto y haremos hincapié en la relación que existe entre la opinión pública y los medios de comunicación, centrándonos, concretamente, en ver la relación que se puede establecer entre la prensa y la opinión pública. A continuación, pondremos un ejemplo concreto, el impacto del discurso de Obama en la opinión pública, basando nuestra reflexión, principalmente, en la consulta de fuentes hemerográficas españolas.

\section{LA OPINIÓN PÚBLICA}

\subsection{El concepto «opinión pública»}

El concepto «opinión pública» es un término polisémico complejo sobre el que hallamos un debate permanente. No existiendo una definición aceptada del término, sino múltiples interpretaciones del mismo, éste ha sido examinado desde distintos ámbitos 
como el de la ciencia política, del derecho, la psicología social, la sociología, la historia, las ciencias de la educación, la filosofía, la filología y las ciencias de la comunicación.

El concepto «opinión pública» implica con el término de «pública» nociones como universalidad, objetividad y racionalidad aunque, a veces, la propia idea de opinión sugiere fluctuación e incertidumbre. La noción de que la opinión pública trasciende la opinión individual y refleja un valor común abstracto, más que un mero compromiso de intereses individuales, continúa influyendo en el pensamiento sobre la opinión pública hasta el siglo XXI. Es decir, «la opinión pública es uno de los muchos fenómenos en que el todo — la opinión pública como tal— necesita de las partes — las opiniones y actitudes individuales - pero sobrepasa la suma de las mismas»².

Los regímenes políticos representativos tienen muy en cuenta la opinión pública a la hora de actuar, e intentan manipularla y ponerla a su favor. La opinión pública cuenta. Por ello, las clases gobernantes vigilan la opinión pública o bien para no despertar su recelo, protesta u oposición, o bien, a veces, para movilizarla en un sentido determinado. Según explica David Hume: «no hay nada que sustente a los gobernantes; sino la opinión. Es, por tanto, sobre la opinión, sobre lo único que el gobierno se sustenta $»^{3}$. Sin embargo, Hume idealiza el papel y la fuerza de la opinión pública. Convendría matizar que a los gobernantes no sólo les sustenta la opinión pública, sino también el propio poder, el dinero, el clientelismo, el partido y sus mecanismos para alcanzar y mantenerse en el poder, y «los poderes fácticos», tales como la Iglesia, el Ejército, las organizaciones empresariales y sindicales y el funcionariado.

En la sociedad contemporánea existe un gran interés por la nueva fuerza de la opinión pública. Según Elizabeth Noelle-Neumann, directora del Centro de Investigación de la Opinión Pública de Allensbach (Alemania), la opinión pública es una forma de ejercer el control social en la que el individuo se ve determinado por el grupo, llegando a ceder a veces, ante el temor de quedarse aislado. Este miedo al aislamiento del individuo pone en marcha «la espiral del silencio» ${ }^{4}$, Esta autora describe la opinión pública como «la opinión dominante que obliga a la sumisión de actitud y de conducta en cuanto amenaza al individuo disidente con el aislamiento, al político con la pérdida del respaldo popular», y considera a los medios de difusión como creadores de opinión pública; «ellos proveen la presión ambiental a la cual la gente responde con presteza, con aprobación, o con el silencio» ${ }^{5}$. Igualmente, se puede percibir que hay personas que contestan con desagrado, rechazo y protesta.

El concepto de opinión pública es a menudo expresión de moralidad colectiva, y se asocia a una fuerza ética por considerar que refleja los valores de todo un conjunto de personas, «el pueblo soberano», pero esto es característico sólo de los regímenes democráticos. Antes de las democracias también se imponían y se promovían públicamente éticas que pretendían representar a «todo» el pueblo — incluso a todo Occidente- Como ejemplo cabe señalar la ética religiosa propagada por la Iglesia católica.

2 Monzón Arribas, Cándido (1987): La opinión pública. Teorías, concepto y métodos. Madrid, Tecnos, p. 143.

${ }^{3}$ Hume, David (1963): Essays Moral, Political and Literacy. London: Oxford University Press, p. 29.

${ }^{4}$ Noelle-Newmann, Elisabeth (1995). La espiral del silencio. Barcelona: Editorial Paidós, 1995, p. 63.

5 Ibidem. «The Spiral of Silence: A Theory of Public Opinion». En: Journal of Communication. Vol. 24:2 (Spring 1974), pp. 43-51.1974, p. 51. 
La opinión pública se suele identificar con lo común, lo consensuado, lo mayoritario, lo dominante, los valores básicos abstractos de una sociedad o cultura. Por tanto, se suele «apelar» a la opinión pública en defensa de «causas justas». Además, «la opinión pública» puede ser compatible con «varias opiniones públicas», con diferencias entre sí, y con «una opinión pública» que exprese los valores compartidos por un grupo de individuos unidos por estos intereses en un colectivo que promueve su opinión públicamente, o bien una opinión sostenida públicamente por un solo individuo.

Algunos autores puntualizan que la opinión pública «no es la suma de las opiniones, ni siquiera de las más importantes, sino la búsqueda de lo que podíamos denominar «la opinión dominante» ${ }^{6}$. Cuando existe unanimidad o un consenso mayoritario tiene lugar la «opinión común» ${ }^{7}$. No obstante, cuando brota el debate, «la opinión pública entra en acción» y «los ciudadanos ejercen el derecho a expresar sus discrepancias» ${ }^{8}$. Según Raúl Rivadeneira Prada, la opinión pública es, por su formación

un producto de opiniones individuales sobre asuntos de interés común y que se origina en las formas comunicativas humanas, en procesos individuales, primero, y en procesos colectivos, después, en diversos grados, según la naturaleza de las informaciones compartidas por los individuos, a la vez que influidas por los intereses particulares de los grupos afectados. La suma de opiniones da por resultado múltiples opiniones, no una sola opinión pública que, para ser tal, necesitaría de la funcionalidad organizada dentro de un clima apto de opinión, para convertir ese cúmulo de opiniones en producto organizado?

\subsection{La prensa como reflejo de opinión pública}

En cuanto a las relaciones entre la opinión pública y la prensa, numerosos autores —historiadores, sociólogos, publicistas, políticos, analistas- han señalado la íntima relación existente entre ambas. A título orientativo podríamos citar a José Luis Dader, quien observa que existe una tendencia «en el mundo de las ciencias sociales a la progresiva decantación de un perfil de investigación y reflexión que estudia las relaciones entre los medios de comunicación y la esfera pública, tanto en su vinculación y repercusión política como en las transformaciones generales o de base que afectan al sistema social» ${ }^{10}$. Abundando en la misma idea, se puede afirmar que el influjo mutuo entre el medio de comunicación y el público produce la opinión pública: «proceso, en el curso del cual los individuos expresan sus actitudes y los grupos llegan a tomar una decisión» ${ }^{11}$.

${ }^{6}$ EnCISo Recio, Luis Miguel: prólogo del libro de Celso Almuiña. La prensa vallisoletana durante el siglo XIX (1808-1914). Valladolid: Instituto Cultural Simancas, 1977, p. 15.

7 MonZón Arribas, Cándido, 1987, p. 148.

8 Ibidem.

9 RIVADENEIRA PRADA, Raúl (1979): La opinión pública (análisis, estructura y métodos para su estudio) México: Editorial Trillas, p. 115.

10 Dader García, José Luis (1986):Opinión pública y periodismo: claves para una reflexión crítica. Pamplona: Universidad de Navarra, p. 27.

${ }^{11}$ Gomis, Lorenzo (1974): El medio media. La función política de la prensa. Madrid: Seminario y Ediciones, p. 524. 
Según Candido Monzón Arribas,

los medios, en principio median la opinión pública y posibilitan su expresión. El problema radica en saber si es una mediación neutra y fiel, reflejo de las opiniones del público, o si la mediación se convierte en mediatización, reflejo de los intereses de todas las instancias que se crean detrás... Naturalmente, los medios como tal no manipulan ni crean opinión pública, son aquellos actores que crean, dirigen, y actúan a través de aquellos: los líderes, los grupos de presión, las élites y el poder en general» ${ }^{12}$.

Los medios no se limitan a reflejar la opinión pública de un modo pasivo, sino que su influencia sutil e indirecta llega a configurar un clima de opinión que los ciudadanos se ven presionados a compartir ${ }^{13}$. Por ello, la prensa suele ser reflejo de la opinión pública, conformadora de opinión e intérprete de la realidad social. Como señala Teodoro León Gross, la prensa encuentra «en la opinión una de las principales razones de su existencia $\mathrm{y}$, a la vez, un espacio de exclusividad $»^{14}$.

En principio, pues, la prensa tiene dos efectos: refuerza las actitudes vigentes en el público y activa el cambio social. Existe una influencia mutua entre el periódico y el público $^{15}$. La prensa sirve para comunicarse con personas alfabetizadas, para llevarles un mensaje, y, a través del mismo, influir en su opinión para poder intervenir en sus decisiones y actuaciones. Por lo tanto, la prensa puede ser un factor tanto de conservación como de cambio. Según el periodista Walter Lippmann, uno de los pioneros del siglo XX en el análisis de estos conceptos, se pide a la prensa «que actúe sobre una fuerza mística llamada opinión pública... La prensa ha llegado a ser considerada como un órgano de democracia directa» ${ }^{16}$.

Teóricamente, existen dos tipos de información periodística: la descriptiva, en la que el periódico simplemente informa sobre qué ha ocurrido y facilita la noticia, y la evaluativa, en la que el periódico apunta la significación de lo que ocurre introduciendo consciente y abiertamente la opinión. Conviene puntualizar que existen periódicos cuya principal razón de ser es reforzar una determinada ideología o un interés de grupo, profesión, religión, etc. El periódico ejerce una función de interpretación y desempeña una función política, la de la mediación ${ }^{17}$. Es decir, el periodista no sólo transmite las noticias sino que tiende a explicarlas e interpretarlas dando su opinión. Se debe tener en cuenta el grado de precisión de la noticia, su calidad, que un hecho sea presentado como noticia con unos criterios objetivos ${ }^{18}$. No obstante, cuando se transmite una información o bien una opinión existen unos procesos tales como la selección, la omisión, la inclusión, la extensión y la ubicación, que pueden llegar a matizar la «objetividad aparente». En un periódico es fundamental la organización de los contenidos, las páginas, las secciones, y los titulares.

Con respecto a la objetividad — «la posible y deseable no intencionalidad que debe estar presente en el mensaje informativo» — cabe argumentar que nunca se da una infor-

\footnotetext{
12 Monzón Arribas, Cándido, 1987, p. 149.

13 JimÉNEZ SÁNCHEZ, Fernando (1995): Detrás del escándalo político. Opinión pública, dinero y poder en la España del s. XX. Barcelona: Tusquets Editores S.A., p. 30.

${ }^{14}$ LeÓn Gross, Teodoro. El artículo de opinión. Barcelona: Ariel, 1996, p. 3.

15 Gomis, Lorenzo, 1974, p. 525.

${ }^{16}$ Lippmann, Walter [(1922) (1965)]: Public Opinion. New York: Harcourt Brace Jovanovich, p. 229.
} 
mación puramente objetiva. «... Siempre es necesaria cierta interpretación de la realidad para que exista la noticia. La manipulación puede ser mínima pero inevitable ya que se separan y aíslan datos dentro de un continuum» ${ }^{19}$. Además, «se lleva a cabo una operación lingüística para que se produzca la noticia ya que sólo los procedimientos del lenguaje permiten aislar y comunicar un hecho» ${ }^{20}$. Por tanto, ese mismo proceso lingüístico, comunicativo, mediatiza y subjetiviza esa supuesta realidad objetiva. El columnista americano Walter Lippman afirma que cada periódico es el resultado de una serie de selecciones tales como «qué elementos deben imprimirse, en qué posición deben ser impresos, cuánto espacio deben ocupar, qué énfasis tendrán. No existen modelos objetivos aquí. Hay convenciones» ${ }^{21}$. Como apunta Raúl Sohr en esta línea: «a menudo la frontera entre los hechos y las opiniones es borrosa, imprecisa. Para empezar, el trabajo de selección de los acontecimientos que se comunicarán como noticias ya es un hecho interpretativo. Los juicios se expresan tanto por omisión como por el modo en que se destaca una información ${ }^{22}$.

Noam Chomsky revela que los medios de comunicación no son imparciales ni objetivos al interpretar las noticias, ejerciendo una importante y clara función propagandística, y apunta hacia el manejo de los medios y la opinión por los poderosos, quienes «son capaces de sentar las premisas del discurso, decidir qué es lo que se va a permitir ver, oír y pensar al público en general y «manejar» la opinión pública organizando periódicas campañas de propaganda» ${ }^{23}$. Por su parte, Lippman cree que se debe organizar las opiniones públicas para la prensa y no por la prensa, y que esa tarea puede ser llevada a cabo por la ciencia política ${ }^{24}$. Este autor piensa en el mundo americano, le preocupa el secretismo y la manipulación de la información, planteando la hipótesis de que noticia y verdad no son necesariamente lo mismo y deben distinguirse entre sî́25. Según Jacques Kayser, «la prensa escrita es, sin discusión, uno de los medios de comunicación de la opinión pública, uno de los medios que ésta tiene —más o menos ampliamente- de expresarse, así como uno de los medios de acción de los poderes, sin que con esto se entienda simplemente el poder del Estado» ${ }^{26}$.

Existe un tipo de prensa que tiene una clara vocación empresarial, de alcanzar un mayor número de lectores, que no «toma partido» de modo unívoco, sino que procura tomar el pulso general para adecuarse a ello. Por el contrario, la prensa ya de antemano definida ideológicamente tiene planteamientos más complejos, No obstante, se puede dar el caso de que su público lector sea ya cautivo y convencido, y espere una información de acuerdo a sus convicciones ya establecidas. En ocasiones, observamos que existe una afinidad entre emisarios y destinatarios del mensaje periodístico como:

17 Gomis, Lorenzo, 1974, pp. 14 y 98.

18 LipPMANN, Walter, (1922) 1965, p. 229.

19 Martínez Albertos, José Luis (1993): Curso General de Redacción Periodística. Madrid: Paraninfo, p. 45.

${ }^{20}$ Gomis, Lorenzo, 1974, p. 24.

${ }^{21}$ LIPPMAN, Walter, (1922) 1965, p. 223.

22 SoHr, Raúl, 1998, p. 94.

${ }^{23}$ CHOMSKy, Noam: «EE.UU., el control del cuarto poder». El Mundo. Madrid, 13 de febrero de 1992, p. 4.

${ }^{24}$ LipPMANN, Walter, (1922) 1965, p. 19.

25 Ibidem, p. 226.

${ }^{26}$ KAYSER, Jacques (1964): El Periódico: estudios de morfología, metodología y de prensa comparada. Quito, Ecuador: CIESPAL, p. 1. 
«cuando un partido utiliza su propio periódico nos encontramos ante una comunicación directa y unívoca, que se dirige a un público cuya comunidad ideológica con el emisor es dada por descontado. Esto garantiza la descodificación del mensaje en el modo deseado por el emisor ${ }^{27}$.

El periodismo de opinión trata de reforzar o crear una opinión pública, implantar y mantener unos principios determinados. La influencia que ejercen los medios de comunicación — «el cuarto poder» — sobre el público se consigue con más eficacia a través de los géneros de opinión que mediante la información. No cabe la neutralidad: el editorialista se dirige al público en una determinada dirección. El comentario aclara los hechos de la información y, en general, presenta al público el contexto de la noticia con una elaboración personal. La opinión del periódico suele aparecer reflejada en el editorial, artículo sin firmar, y en los artículos firmados. El editorial expresa la opinión asumida por los propietarios, accionistas, el equipo de redacción y grupos de interés afines. Los hechos vienen tamizados por la opinión del propietario del diario, tendiendo no sólo a transmitir ideas, sino también a explicarlas e interpretarlas. El periódico casi siempre comulga de alguna manera con las tesis recogidas en los comentarios, críticas y noticias reunidas en sus páginas. El artículo firmado es ostensiblemente «una» opinión que permite al periódico, por un lado, obtener prestigio general a base de acoger firmas conocidas, autoridades, testigos presenciales, corresponsales, y por otra parte, «alejarse» de esa opinión «personal», no responsabilizándose de ella directamente, pero al mismo tiempo beneficiándose de su voz.

La prensa, a la hora de codificar sus mensajes, trata de adoctrinar y crear opinión pública, pero para ello se atribuye a sí misma la mayor identificación posible con sus lectores, la representación y la calidad de portavoz de la «verdadera» opinión pública. Igualmente, la prensa utiliza el término opinión pública y la identifica con su ideología. A pesar de todo, el periódico ha desarrollado, a lo a largo de su historia, «una serie de tareas que hoy forman parte de sus características esenciales. A ellas pertenece ante todo la universalidad del contenido, lo cual no significa otra cosa que la adaptación a los intereses de gente muy distinta ${ }^{28}$. Por ello, se pueden encontrar múltiples versiones e interpretaciones de unos hechos históricos determinados. La prensa es un medio de expresión de un poder, ya sea éste de tipo religioso, económico, político o social. Las circunstancias sociales y políticas inciden en la información que presenta el periódico, donde queda reflejada la interrelación entre el periódico, el contexto histórico y el contenido ideológico de la noticia. Por todo ello, se llega a afirmar que la prensa «tiene un papel esencial en la difusión de la ideología y en la formación de mentalidades. La finalidad de una publicación puede tener desde un carácter puramente económico a un fin político, puede estar al servicio de un gobierno, de un partido político, de una persona o de un grupo» ${ }^{29}$. Según opina Jean-Michel Desvois, «la prensa es el medio privilegiado de expresión de las ideologías... la prensa no sólo nos informa de cómo pensaban o sentían las élites, sino también, por su naturaleza de medio de comunicación de masas, sobre todo, un sistema

${ }^{27}$ LIDIA, Clara E. (1970): «Notas sobre la prensa anarquista en la Revolución de 1968» en Historia, pensamiento y Literatura. Madrid: Las Américas, p. 3.

28 Dovifat, Emil (1959 y 1960): Periodismo. México: UTEHA, (2 vols.), Tomo I, p. 9.

${ }^{29}$ Desvors, Jean-Michel (1986): «Historia de la prensa: el recurso del método». En: Tuñón de Lara, Manuel (dir.). La crisis de la Resturación. España entre la primera Guerra Mundial y la II República. II Coloquio de Segovia sobre Historia Contemporánea. Madrid: Siglo XXI, 1986, pp. 351-359. 
de mentalidades en un momento dado ${ }^{30}$. En esta línea, Raúl Sohr apunta que «la prensa es un elemento clave para la fijación de la conciencia de los pueblos» ${ }^{31}$. Por consiguiente tiene un gran valor como fuente histórica, pues para un buen estudio de las ideologías contemporáneas hay que contar en gran parte con su estudio ${ }^{32}$.

La prensa llega a gran parte de la población y ofrece la posibilidad de observar la influencia de un mensaje ideológico, tanto en su elaboración como en su difusión. Muchos acontecimientos se utilizan como pretexto para proyectar sobre ellos un conjunto de reflexiones de carácter doctrinal, en torno a la política de un determinado gobierno, los intereses de un grupo, etc. La prensa está en un papel de oposición, crítica, o a favor de una política y, en muchas ocasiones, se convierte en portavoz de los intereses, opiniones e ideales de un sector de la sociedad afín a un determinado rotativo. Estos acontecimientos van a ayudar a desarrollar el corpus doctrinario de una ideología. La deformación de la realidad, generalmente, implica una ideologización. Se manipula una información porque interesa introducir una determinada idea sobre unos hechos concretos. Los órganos de prensa no son simples proveedores de informaciones aisladas. El valor de una información periodística siempre viene tamizado por una serie de aspectos, materiales e ideológicos: materiales que determinan su impacto (cuerpo de los caracteres del título y del texto, emplazamiento en el cuerpo del diario, espacio que ocupa, etc.); ideológicos, que determinan la interpretación explícita o implícita propuesta o sugerida al lector. Por consiguiente, conviene determinar los lazos que unen a la redacción con el público de un diario. Hay que analizar las categorías sociales entre las cuales circula el periódico en cuestión, su gestión, y su equipo de redacción. Así, cuando se trata de un periódico ideológicamente definido, las opiniones presentadas por el redactor coinciden en principio con las de sus lectores.

Según afirma el ensayista y articulista, Joseph María Casasús, «la tan repetida «objetividad» de la información constituye una utopía evidente: porque no existen items inocuos, porque la mayor parte de los [items] empleados en la semantización de las comunicaciones de masas son operadores semánticos involucrados en una enorme tela de significaciones sociales y cargas psicológicas ${ }^{33}$. Por lo tanto, para ponderar las posibles repercusiones de las relaciones ideológicas en la opinión pública es fundamental conocer: el origen de las ideologías, quién financia el periódico y las relaciones que tiene con grupos económicos o políticos, y cuántas personas reciben la comunicación. En definitiva, se advierte que la prensa trata de crear un vínculo estrecho con la opinión pública, siendo consciente de la influencia que puede llegar a ejercer en ella.

\section{ESTUDIO DE CASO: LA ORATORIA DE OBAMA Y SU IMPACTO EN LA OPINIÓN PÚBLICA ESPAÑOLA}

Barack Hussein Obama, el primer presidente electo afroamericano de Estados Unidos, se ha convertido en el líder más internacional y popular de la política estadouni-

30 Desvois, Jean-Michel, 1986, p. 351.

31 SoHr, Raúl (1998): Historia y poder de la prensa. Barcelona: Editorial Andrés Bello Española, p. 22.

32 Ibidem, 1987b, pp. 25 y 26.

${ }^{33}$ CASASÚs, Joseph María (1998): Ideología y análisis de los medios de comunicación. Barcelona: CIMS, p. 125. 
dense, suscitando grandes expectativas dentro y fuera de las fronteras de Estados Uni$\operatorname{dos}^{34}$. Su personalidad carismática y su discurso han calado profundamente, no sólo en la opinión pública estadounidense sino también mundial, como se puede apreciar por enorme eco que han tenido sus discursos y mítines en los medios de comunicación en los últimos dos años, acentuándose, en mayor medida, a partir del 27 de agosto de 2008, cuando Obama recibió la designación oficial como candidato presidencial del partido demócrata ${ }^{35}$. En este ensayo, nos referiremos a cómo se ha proyectado el discurso y la victoria de Obama en el caso español, en un medio de comunicación, la prensa, centrándonos en el caso concreto de la cobertura de la prensa liberal.

El ex senador por Illinois Barack Obama confiesa en su autobiografía, a raíz de la reacción positiva que tuvo su discurso en la opinión pública en la Convención demócrata de Boston en el año 2004, que se metió en política «para tener alguna influencia en el debate público», porque pensaba que tenía algo que decir sobre la dirección en la que Estados Unidos necesitaba ir como país ${ }^{36}$. Por ello, no sorprende que su estrategia y la de sus colaboradores haya sido la de tratar de ganarse la opinión pública. Durante la campaña electoral, Obama trabajó duramente para adquirir popularidad, lo cual no le fue difícil, porque simbolizaba el cambio, a diferencia de MacCain que significaba la continuidad. Además, Obama presentaba un discurso de multilateralismo contrario a las ideas de Bush, el presidente que ha gozado de menos popularidad en la historia de los Estados Unidos.

Ante los grandes retos que le esperan a Obama, los historiadores han hecho, especialmente, referencia a dos presidentes que, como él, llegaron al poder en situaciones complejas: a Abraham Lincoln, cuando se hizo cargo de la presidencia a punto de empezar la guerra civil, y Franklin Delano Roosevelt, que heredó una situación similar de crisis económica tras la Gran Depresión de 1929. En cuanto a la retórica de Obama, ésta enlaza con la de los líderes presidenciales que hemos mencionado, y a los que cabe añadir la figura de John F. Kennedy. Obama sabe recrear el lenguaje de los discursos acreditados de estos presidentes, siendo «la expresión más acabada del arte de presentar ideas conocidas con una envoltura diferente ${ }^{37}$. Por lo que respecta a Lincoln, sus discursos históricos, como el de «House Divided» («Casa Dividida») o el de Gettysburg, han sido una clara fuente de inspiración. Así, en su discurso «A more perfect Union» («Una unión más perfecta») Obama apelaba a la unidad, tratando de fortalecer la nación Americana, evitando la división en el pueblo americano, y emulaba a Lincoln cuando ante la amenaza secesionista decía: «Una casa dividida contra sí misma, no puede permanecer» ${ }^{38}$.

La prensa española liberal alude constantemente a la comparación entre Obama y F. D. Roosevelt, «Obama va a ser un nuevo Franklin Delano Roosevelt, el presidente que hizo frente a la crisis de 1929 con el New Deal, redibujando las fronteras de lo público y

${ }^{34}$ Véase, a título de ejemplo: «El mundo acoge con esperanza la elección de Barack Obama». La Voz de Galicia, 6-11-2008, p. 1; «Obama refunda el sueño americano» p. 2 y « El cambio llegó a Estados Unidos», p. 3.

35 «La primera familia aprende a vivir en una burbuja». Selección en El País 27-11,2008 p. 3.

36 Traducción de la autora: «I got into politics to have some influence on the public debate, because I thought I had something to say about the direction we need to go as a country». Barack Obama. The Audacity of Hope. New York: Canongate, 2008, p. 359.

37 Aguado, Sergio: «El “juggernaut” americano». El País, 13-11-2008, p. 31.

38 Discurso de Abraham Lincoln «House Divided» ante la convención republicana el 16 de junio de 1956. 
lo privado» ${ }^{39}$. Al igual que hizo Roosevelt, Obama ha prometido y anunciado que la prioridad de sus primeros días de gobierno será la de aprobar un paquete de medidas para remontar la crisis que ha calificado de «proporciones históricas» ${ }^{40}$. Si en el discurso inaugural Roosevelt transmitía la idea de que lo único que se debía temer era el miedo mismo ( The Only Thing We Have to Fear is Fear Itself») y expresaba el compromiso de acabar con la parálisis política, dando confianza y apartando el miedo, ofreciéndose un liderazgo lleno de vigor, del mismo modo, Obama hizo un llamamiento al electorado para que el pueblo americano depositase su confianza en su liderazgo para salir de la crisis económica, política, social, y moral.

Sus palabras han invitado constantemente al diálogo. En su discurso sobre la raza pidió a la gente que continuase «la marcha que comenzaron aquellos que vinieron antes» para alcanzar la igualdad, en una clara alusión a Martín Luther King, Jr. Asimismo, vemos cómo narra su historia: «Yo soy el hijo de un hombre negro de Kenia y de una mujer blanca de Kansas... y, hasta mi último día no olvidaré jamás que mi historia no hubiera sido posible en ningún otro país del mundo... ${ }^{41}$. Como afirmaba Lluís Bassets,

Estamos ante un excelente narrador. Un hombre que sabe contar historias. Que lo hace con énfasis y con pasión. Pero sin desbordarse ni desafinar con una nota excesiva. La contención y la moderación forman también parte de su estilo. Durante esta larga campaña, la más larga de la historia, no ha cesado en ningún momento de contar historias, apólogos sacados de la vida real con los que transmite ideas y propuestas ${ }^{42}$.

Este discurso tuvo un enorme eco en la prensa española, transmitiendo la aspiración de Obama a terminar con las divisiones y desigualdades, proponiendo como desafío cambiar la situación presente.

Otro factor decisivo y clave en su discurso, fue la elección de un lema afortunado, haciendo honor al significado de su nombre Barack. El eslogan tiene fuerza, es poderoso: «Yes, we can» («Sí, podemos»), como se ha demostrado al saberlo utilizar en cada uno de sus discursos ${ }^{43}$.

Ante el discurso esperanzador de Obama, y la ardua tarea a la que se debe enfrentar, The New York Times publicaba una semana después de su elección:

El paso de la retórica de la campaña a la realidad podría resultar muy complicado. Y los inflamados discursos de Obama han creado tales expectativas que existe un gran riesgo de caer en la decepción. Ha hablado de una «nueva política» que reúna republicanos y demócratas. Pero si colabora con los republicanos para lograr un acercamiento de posiciones en asuntos como Irak, el terrorismo y el cambio climático, corre el riesgo de alejarse de su base progresista ${ }^{44}$.

\footnotetext{
39 «Todos a Washington» por José Ignacio Torreblanca. El País, 10-11-2008, p. 4.

40 «Obama promete una fuerte inversión pública ante la crisis». El País, 25-11-2008, p. 4.

${ }^{41}$ Senator Barack Obama's Race Speech «A More Perfect Union». 18 de marzo de 2008, pronunciado en el Constitution Center, Philadelphia, Pennsylvania.

42 Bassets, Lluís: «Obama, actor y guionista». El País, 31-10-2008, p. 4.

${ }^{43}$ Véase, por ejemplo, el discurso tras las Primarias de Iowa y el de New Hampshire en enero de 2008 o el de Chicago de noviembre de 2008.

${ }^{44}$ «La parte difícil: de la retórica a la realidad». The New York Times. Selección de El País, 13-11-2008, p. 4.
} 
En general, la prensa destaca el talento y la fuerza de inspiración del mensaje que transmite Obama. Así, Antonio Basagoiti, declaraba «el País Vasco tendrá algún día a su Barack Obama. No me refiero al color de la piel, sino al color de las ideas ${ }^{45}$. Por su parte, en un artículo de opinión, el escritor chileno Jorge Edwards confiesa que supo de la existencia de Obama a través de transmisiones de la televisión chilena y cómo le

sorprendió en profundidad su oratoria: tranquila, perfectamente controlada, dotada de algo que podríamos definir como una pasión fría, con un gran dominio del lenguaje y con ideas claras, ambiciosas, entregadas en una síntesis rigurosa, personal, a veces hasta confesional, y sin entrar nunca en minucias ${ }^{46}$. Además, ha destacado su conducta tranquilizadora:

«bajo la intensa luz de la campaña electoral, su comportamiento hace pensar en una persona considerablemente serena y confiada a pesar de la enorme presión, aunque también en alguien que raramente se desvía del metódico camino que ha decidido seguir» ${ }^{47}$.

Con respecto a su lenguaje, Obama ha hecho llegar siempre un mensaje de «moderación y mesura endulzado por una sonrisa fácil y un lenguaje educado, articulado y asentado en la lógica; lo apropiado para atraer a moderados e indecisos $»^{48}$. Asimismo, en el rotativo El País se difunde la imagen de que Obama es un político innovador y renovador, haciendo hincapié en el uso de la tecnología, internet y la banda ancha, que fue utilizada intensivamente por Obama para difundir ideas, comunicarse, organizarse y recoger pequeños donativos ${ }^{49}$. El diario El País pone la campaña de Obama como modelo en unas elecciones, apuntando a cómo ésta supo influir en la movilización de los votantes:

El equipo de Obama supo capitalizar temprano el uso creciente de la red. En el curso de la campaña reunieron más de 10 millones de direcciones de correo...la victoria de Barack Obama se debe en buena medida al hecho de que supo resolver dos problemas claves: dejar una real autonomía organizativa a sus simpatizantes sin que afecte su propia capacidad de transmitir su propio mensaje a los activistas, por una parte. La capacidad, por otra, de transformar la simpatía manifestada en la red en acción en el mundo físico, desde el trabajo de terreno para convencer a los indecisos hasta la movilización el día de las elecciones para cerciorarse que fueran a votar ${ }^{50}$.

Obama ha sabido aprovechar las posibilidades de internet en una campaña bien dirigida por David Axelrod ${ }^{51}$. A esto se añaden, como afirma Greg Pinelo, responsable de equipo que produjo la publicidad audiovisual del candidato demócrata, su magnetismo y su capacidad de dar emoción a las palabras ${ }^{52}$. Según opina el abogado internacional y escritor británico Philippe Sands, al ser Obama un hombre que ha vivido y se ha educado en

\footnotetext{
45 «Seguro que Euskadi tendrá algún día a su Barack Obama». La Gaceta. 13-11-2008, p. 9.

46 Edwards, Jorge: «Cambio de folio». El País, 9-11-2008, p. 39.

${ }^{47}$ Ibidem.

48 Aguado, Sergio. «El “juggernaut” americano». El País, 13-11-2008, p. 31.

49 Ibidem.

${ }^{50}$ PISAN, Francis: «Lecciones y retos de la victoria de Barack Obama». El País 13-11-2008, p. 2.

51 Calvo, José Manuel: «Un antes y un después» por El País, 5-11-2008, p. 4.

52 XimÉnez SAndoval, Pablo: «Obama era rico cuando Mc Cain se arruinó». El País, 21-11-2008, última pá-
} gina. 
distintos continentes, proyecta una dimensión multirracial, multiétnica y multinacional, por lo cual las personas ponen «algún hilo de sus propios ideales y esperanzas» en él ${ }^{53}$.

Obama es consciente del poder de los medios de comunicación en la formación de la opinión pública, destacando entre sus habilidades políticas la de su manejo de ésta y su poder para conectar con el público, haciéndole sentirse partícipe de sus aspiraciones. La relación de Obama con la gente parece esencial para él, y prueba de ello es que ha abierto un sitio web -Change.gov- en el cual promete informar sobre su programa y equipo de transición. Un blog mantendrá al público informado sobre el proceso y los ciudadanos están invitados a compartir sus ideas sobre el futuro del país ${ }^{54}$. Se percibe cómo aspira a ser un gran comunicador, como lo fue Roosevelt. En este sentido, vemos similitudes con el estilo presidencial de Franklin D. Roosevelt, quien utilizaba la radio para difundir su programa con las charlas junto al fuego, propagando una imagen muy humana, como trata de hacer Obama empleando una herramienta tan novedosa como internet. «Obama ha demostrado ser un jefe de campaña tranquilo pero temible, de pulso firme y cabeza fría», siendo «portador de un mensaje transversal muy fuerte, reforzado por el reconocimiento que está recibiendo desde el campo republicano como presidente de todos y encarnación del ascenso social, el sueño americano que lleva a un afroamericano a lo más alto» ${ }^{55}$. Sin duda, los afroamericanos que lucharon por los derechos civiles sintieron la satisfacción ante la victoria de Obama, el primer afroamericano presidente de Estados Unidos. La capacidad de su oratoria se pone de relieve en la prensa liberal en artículos y titulares: «Obama ha demostrado ya en otras ocasiones su capacidad para revertir con un vibrante discurso el rumbo de los acontecimientos $»^{56}$ y se hace a alusión a cómo «habla con la elocuencia, claridad y amplitud de vocabulario del más eminente abogado o profesor universitario» ${ }^{57}$. Se le describe como «el gran orador», explicando que cuando se dirige a la comunidad afroamericana hace llamamientos a la responsabilidad personal con un mensaje no victimista ${ }^{58}$.

Ante la histórica victoria de Obama y cómo el mundo la ha acogido con esperanza, el historiador Paul Kennedy hizo alusión a la política de poder blando defendida por el profesor de Harvard Joseph Nye, que consideraba que «un estilo de vida atractivo, una cultura interesante, la capacidad de ir de la mano de la opinión mundial en vez de ir en su contra podían ser unas herramientas tan útiles para un país como la habilidad de los diplomáticos, la solidez financiera e incluso los grandes portaaviones», aconsejando a Obama que estudiase con detalle «la retórica y las políticas de sus antecesores Wilson, FDR y JFK...» porque

ninguno de estos estadistas hizo nada más que defender los intereses «nacionales» de Estados Unidos. Lo que tuvieron en común fue el genio y la inteligencia para saber combinar lo que convenía al mundo, al menos, a grandes partes de él. Convencieron a millones de personas en

53 Ibidem.

${ }^{54}$ PISAN, Francis: «Lecciones y retos de la victoria de Barack Obama» por El País, 13-11-2008, p. 2.

55 BAssets, Lluis: «El País donde todo es posible» por El País, 6-11-2008, p. 9.

56 «Obama gana una histórica nominación». El País, 28-8-2008, p. 2.

57 CARLIN, John «Un hombre para la eternidad». El País, 6-11-2008, p. 15.

58 Léase: «La noche del gran orador». El País, 28-8-2008, p. 3, «Con Obama ganamos un socio en ahorro energético». El País, 21-11-2008, p. 5, «Nunca más negros». El País, 7-11-1008, p. 8. 
todo el planeta de que debían tener fe en el compromiso, el juicio y el liderazgo de EEUU y, por consiguiente, tomarse en serio las propuestas reformistas nacidas de la Casa Blanca ${ }^{59}$.

Por su parte, el escritor chileno Jorge Edwards afirmaba que «no es seguro a buenas cuentas, que la presidencia de Obama sea una gran presidencia, al estilo de los períodos de un Abraham Lincoln o de un F.D. Roosevelt, pero es evidente que tiene la posibilidad cierta de convertirse en uno de los grandes presidentes norteamericanos, cosa que influiría en el resto del mundo y nos interesa a todos ${ }^{60}$.

La prensa liberal destaca, pues le conviene a sus intereses empresariales, el hecho, al día siguiente de las elecciones, es decir, el día 5 de noviembre de 2008, de que el pueblo americano acudiera masivamente a comprar el periódico, habiendo colas y reventas a pesar de haber tenido acceso a la noche electoral televisada y al discurso de Obama ${ }^{61}$.

$\mathrm{Su}$ victoria ha marcado un hito en la historia de Estados Unidos pues constituye la constatación de que el sueño americano de que cualquier ciudadano sin distinción de raza, credo o género puede acceder a la presidencia y así lo expresó Obama en su discurso de aceptación la madrugada de miércoles 5 de noviembre: «Sólo en Estados Unidos una persona con mis antecedentes puede llegar a ocupar la más alta magistratura del país». Sigue siendo el país de las oportunidades ${ }^{62}$. En este memorable discurso, Obama recreó los mitos fundacionales «sueño de nuestros fundadores», el mito de Estados Unidos como país de la esperanza, como nación elegida, del poder de los ideales de democracia y libertad y retomó la famosa frase del discurso que pronunció Lincoln en Gettysburg en 1863: «hemos conseguido demostrar que doscientos años después, el Gobierno de la gente y para la gente no ha desaparecido de la tierra, esta es vuestra victoria ${ }^{63}$. El discurso transmitía ilusión y esperanza, apelando continuamente a la unidad, repitiendo la idea de que no hay Estados Republicanos o Estados Demócratas. Sólo hay los EEUU de América. Finalmente, cabe señalar el trasfondo religioso y el hecho de que, como todos sus antecesores, Obama terminara con el clásico «QQué Dios les bendiga y qué Dios bendiga a los Estados Unidos de América!».

La prensa liberal de provincias también informa del enorme impacto que produjo el presidente americano. Así, La Voz de Galicia expresa su confianza y su simpatía con los contenidos y la opción de Obama. En un artículo, este diario presenta la imagen de un presidente electo carismático que busca el diálogo, que «luce un carisma que hace daño a la vista y un talento para la palabra que parece de un predicador», siendo, a los ojos del mundo, «el hombre de todas partes y de ningún sitio, el rostro global» que «convierte con una facilidad increíble una tarima y un micrófono en un altar» ${ }^{64}$.

59 KenNEDY, Paul: «Regresa el «poder blando». El País ,19-11-2008, p. 37.

${ }^{60}$ Edwards, Jorge: «Cambio de folio». El País, 9-11-2008, p. 39.

61 «EE.UU. hace cola para leer la noticia en los periódicos. Los diarios se convierten en objeto de colección y agotan todas sus ediciones». El País, 7-11-2008.

62 Discurso de Obama en Grant Park, Chicago «Yes We Can» (Véase la traducción en El País, 6-112008 , pp. 6 y 7 ).

${ }^{63}$ Esta frase está tomada del discurso que Lincoln dio en Gettysburg el 19 de noviembre de 1863 . Traducción de la autora: «que el gobierno del pueblo, por el pueblo, no desaparecerá de la faz de la tierra» (The Gettydburg Address: «That the government of the people, by the people, for the people, shall not perish from the earth»).

${ }^{64} \mathrm{La}$ Voz de Galicia, César Casal «El predicador de la esperanza» 6-11-2008, p. 4. 
Al igual que ocurrió con Roosevelt en 1933 o con Kennedy en 1960, Obama ha llegado a las urnas acompañado de una movilización popular extraordinaria ${ }^{65}$, como pone de relieve el diario El País que apoyó la elección de Obama a la presidencia. Si comparamos las elecciones de Kennedy y Obama vemos cómo la victoria de ambos ha respondido al anhelo de un electorado que deseaba una nueva política, a la voz popular que expresaba que había que «cambiar el camino» ${ }^{66}$. La idea de que Obama ha inspirado un momento de cambio aparece con frecuencia en el diario El País que, aludiendo positivamente a la promesa de cambio de Felipe González, se hace eco de su propia ideología ${ }^{67}$. Obama plantea que se puede cambiar, pero — como también hacía JFK - incide en que hay un largo camino, en que los deseos y esperanzas no se pueden cumplir de golpe. Encontramos resonancias del discurso de JFK en el de Obama en Chicago: «Sabemos que el Gobierno no puede resolver todos los problemas. El camino que tenemos por delante será largo. Puede que no lleguemos al final de un año o incluso en un mandato» ${ }^{68}$. Además, al igual que ocurrió con John F. Kennedy, Obama ha tenido un apoyo masivo de los jóvenes, aunque «el apoyo decisivo vino de una amalgama de personas de todas las generaciones, grupos étnicos e ideologías políticas, motivado por la crisis económica y la insatisfacción con la política de George W. Bush ${ }^{69}$.

Si ya en la campaña electoral de 2008, la prensa liberal española había elogiado al candidato a la presidencia, Obama, manifestando así sus preferencias ideológicas, ante su victoria se le dedican un extenso número de páginas e ilustraciones. Al publicarse la noticia sobre su victoria, llama la atención del lector la extensa cobertura que recibe en el diario El País respecto al resto de los diarios nacionales ${ }^{70}$.

El discurso de Obama tras su victoria en la jornada del 4 de noviembre de 2008, según refleja El País, «no fue una intervención simplemente emotiva, sino un excelente discurso político en el que la retórica estuvo al servicio de las ideas y los compromisos, expresados con la intención de pasar una página sombría de la historia de Estados Unidos, sin humillar, por otra parte a sus responsables, expresando así su deseo de recomponer la unidad $^{71}$. No obstante, según M. Á. Abstener, «no está nada claro que el resultado del 4 de noviembre implique el pleno levantamiento del tabú racial», para él «la elección se

65 «Una gran movilización impulsa a Obama. El senador demócrata reúne a miles de personas en cada mitin que celebra». El País, 31-10-2008, p. 2.

${ }^{66}$ Léase: «Si triunfara Kennedy» por Luis de Zulueta. El Tiempo, Bogotá, 8-XI-1960.

${ }^{67}$ Léase: «PROBST SALOMÓN, Barbara. Estados Unidos pasa la página», 2-4-2008, p. 27.

68 All this will not be finished in the first one hundred days. Nor will it be finished in the first one thousand days, nor in the life of this Administration, nor even perhaps in our lifetime on this planet. But let us begin. John F. Kennedy. Inaugural Address. 20 de enero de 1961. Traducción de la autora: «Todo esto no se acabará en los primeros cien días. No se logrará en los primeros mil días; ni siquiera se conseguirá en la vida de esta Administración, ni siquiera quizás en toda la vida en este planeta. Pero empecemos».

${ }^{69}$ «Ni los sondeos fallaron ni el efecto Bradley apareció» por Rosa Paíno. La Voz de Galicia, 6-11-2008, p. 5.

${ }^{70}$ Sobre la victoria de Obama podemos destacar los siguientes titulares: «Obama culmina el sueño del cambio» y «El cambio ha llegado a América» (El País), «Obama cambia el color de la historia» (El Mundo), «Estados Unidos abre una nueva era con Barack Obama, el primer presidente negro de su historia». La Vanguardia); «El cambio ha llegado» $(A B C)$; «El mundo acoge con esperanza la elección de Barack Obama» y «Obama refunda el sueño americano» (La Voz de Galicia); «Obama se presenta como ejemplo del sueño americano» ( $L a$ Razón).

${ }^{71}$ «Banderas de esperanza. Obama inaugura un liderazgo norteamericano que merece confianza y cooperación». El País, 6-11-2008, p. 32. 
debe a una evolución demográfica» de los votantes. Con una participación elevada, del $62 \%$ del electorado (Kennedy $67 \%$ ). Le han votado un $43 \%$ de blancos, el mismo porcentaje que obtuvo Kerry, pero un $96 \%$ de los negros y un $66 \%$ de hispanos», y sostiene: «si hubiera habido una emigración notable de votos blancos al presidente electo, estaríamos ante una revolución; si lo que ha cambiado es la demografía para permitir que hispanos y negros decidan elecciones, es una evolución $\gg^{72}$.

Tras las elecciones, Obama continúa transmitiendo el mensaje de esperanza de poder remontar la situación en la tercera rueda de prensa ${ }^{73}$. No obstante, afirma El País, «los republicanos ya han criticado «el propósito de Obama de estrenarse, a lo Roosevelt, con un fuerte paquete de inversión pública en infraestructura y ayudas sociales» ${ }^{74}$. Obama pide dejar de derrochar «Si invertimos en lo que necesitamos, como la renovación de las fuentes de energía o la tecnología, tenemos que dejar de derrochar en aquello que no necesitamos» ${ }^{75}$. Las palabras recuerdan las que pronunció el Presidente Jimmy Carter en un discurso sobre la Crisis de confianza, en el que pedía al pueblo americano que se esforzara con sacrificios para solucionar la crisis.

De modo semejante a Roosevelt cuando se rodeó del «Brain Trust», o de la misma forma hizo John F. Kennedy, Obama también ha elegido a los más capaces para formar parte de su gabinete. En el equipo domina la experiencia. Obama dice al respecto:

Cuando busco los mejores para servir a Estados Unidos, no voy pidiendo la filiación política...Cuando se trata de proteger nuestra nación no somos republicanos ni demócratas, somos americanos, porque ningún partido tiene el monopolio del poder y la sabiduría»... «Todos ellos comparten mi pragmatismo sobre el uso del poder y mis ideas sobre el papel de EEUU como líder mundial»... «He juntado este equipo porque creo en las personalidades fuertes con opiniones contundentes. Uno de los peligros en la Casa Blanca es el de que todo el mundo piense igual y no haya sobre lo que discutir. Yo quiero un debate encendido. Pero que quede claro que yo, como presidente, fijaré la política a seguir. Yo seré el responsable de la visión que este equipo se encargue de difundir ${ }^{76}$.

En relación con la formación de su equipo, donde se puede prever el estilo de gobierno $^{77}$, explica que el único criterio que está guiando sus nombramientos es el talento:

Cuando la gente mire atrás y vea el cuadro completo, creo que dirán que es uno de los Gobiernos y equipos de la Casa Blanca más diverso de todos los tiempos. Pero lo más importante que dirán es que son todas personas con una extraordinaria preparación y excelencia. Una de las creencias más fuertes que he tenido a lo largo de toda mi carrera es que no hay contradicción entre la diversidad y la excelencia ${ }^{78}$.

72 «a $®$ evolución de B.H.O.». El País, 12-11-2008, p. 4.

73 «Obama: La ayuda contra la crisis está en camino». El País, 7-11-2008, p. 7.

74 «Obama eliminará los gastos superfluos». El País, 26-11-2008, p. 3.

75 «Obama eliminará los gastos superfluos». El País, 26-11-2008, p. 2. Léase el discurso de Jimmy Carter. Crisis of Confidence pronunciado el 15 de julio de 1979.

76 Discurso de presentación de sus colaboradores del día 1-12-2008, en El País, 2-12-2008.

77 «Decálogo para entender a Obama». El País, 3-12-2008.

78 «Obama elige al hispano Bill Richardson como nuevo secretario de Comercio». El País, 4-12-2008, p. 6. Entre las figuras clave elegidas por Barack Obama para formar parte del nuevo gobierno de Estados Unidos encontramos las siguientes; Joe Biden, vicepresidente, ex senador por Delaware. En el equipo económico: Ti- 
Según Patrick Healey, «Obama...cree que varias mentes son mejor que una y, a pesar de toda su habilidad como orador, recela del exceso de exhibicionismo» ${ }^{79}$. Para el historiador británico Tristam Hunt, Obama «aporta la idea a la que todo el mundo quiere volver: que Estados Unidos es una tierra de oportunidades y posibilidades extraordinarias, donde los milagros ocurren»y, añade, «la elección de Obama ha producido en la mayoría de los no estadounidenses la sensación de que...ha visto los errores de su proceder a lo largo de los últimos ocho años y ha cambiado de rumbo» ${ }^{80}$. A Obama le espera una tarea ingente «que seguramente trasciende cualquier programa político o crisis exterior. Se hace cargo de una nación cansada del pasado y desconfiada ante el futuro, pesimista respecto a su lugar en el mundo, cínica respecto a su gobierno y desesperada por sentirse un poco más liberada de sus problemas» ${ }^{81}$. Por su parte, el historiador Michael Beschloss manifestaba que Obama era consciente de que, en el año 2008, el país necesitaba «una cura», y añadía: «ha sido una década muy dura, empezando por un controvertido juicio político y, luego, el recuento, el 11-S, las guerras de Afganistán e Irak, el Katrina y, ahora, la crisis financiera. Al pensar en el impacto que todas estas cosas han tenido sobre el sistema a lo largo de estos 10 años, creo que Obama es consciente de que realmente necesita calmar nuestros ánimos» ${ }^{82}$.

La actitud de Obama no está siendo pasiva después de su elección y, en este sentido, no parece estar siguiendo el ejemplo de Roosevelt que esperó hasta la fecha de traspaso de poderes para empezar a dar soluciones. La solución de la crisis económica es la prioridad del gobierno de Obama. En este punto, podemos ver semejanzas con el programa del New Deal de Roosevelt en el que el tema que primero se abordó fue el restablecimiento del orden económico. Por ello, no se podrán abordar otros proyectos, como invertir en energías verdes, cerrar el campo de prisioneros de Guantánamo o retirar las tropas de Irak en un plazo breve.

Por último, se observa que la prensa liberal española pone de relieve la idea de que Obama pretende recuperar el liderazgo internacional de EE.UU., citando las palabras que pronunció en una conferencia de prensa en Chicago:

En este mundo incierto ha llegado la hora de un nuevo comienzo, un nuevo amanecer del liderazgo americano para enfrentar los desafíos del siglo XXI. Fortaleceremos nuestra capacidad para derrotar a nuestros enemigos y apoyar a nuestros amigos. Renovaremos las viejas alianzas y forjaremos nuevas y duraderas sociedades. Demostraremos al mundo que Estados

mothy Geithner, Secretario del Tesoro, Lawrence Summers, Director del Consejo Económico Nacional, Christina Romer, Responsable del Consejo de Asesores Económicos, Meter Orszag, Jefe de la Oficina del Presupuesto, Melody Bernes, Directora de la Oficina de Política Doméstica, Paul Volcker, Presidente Consejo Asesor para la Recuperación Económica. En el equipo de seguridad y exteriores; Hillary Clinton, Secretaria de Estado, Eric Holder, Fiscal General, Robert Gates, Secretario de Defensa, Janet Napolitano, Secretaria de Seguridad Nacional, Susan Rice, Embajadora en la ONU, James Jones, Consejero Nacional de Seguridad, y Bill Richardson, Secretario de Comercio, el gobernador latino de Nuevo México.

79 «La crisis pone a prueba el liderazgo de los candidatos». The New York Times. Selección de El País, 9-102008, p. 1.

${ }^{80}$ «Para muchos no estadounidenses, un ideal renovado». The New York Times. Selección de El País, 13-112008 , p. 5.

${ }^{81}$ «La parte difícil: de la retórica a la realidad». The New York Times. Selección de El País, 13-11-2008, p. 4.

82 Ibidem. 
Unidos es implacable en la defensa de su pueblo, firme en la promoción de sus intereses y comprometido con los ideales que iluminan como un faro al mundo, la democracia y la justicia, porque los valores americanos son el mejor producto de exportación de este país ${ }^{83}$.

\section{Conclusiones}

Las prensa liberal española muestra cómo está pendiente de todos los pasos que está dando Obama para salir de la grave situación económica en la que se ve inmersa y cómo entiende que la importancia del mandato de Obama no es sólo a escala de Estados Unidos sino mundial. Parece que se intenta encaminar a la opinión pública española a que plantee el beneficio que la política de Obama puede traer a España. Se hace hincapié en la idea de que Obama simboliza un cambio de rumbo respecto a la política conservadora que se estaba haciendo, destacando su gran capacidad comunicadora, su prestigio y popularidad. El hecho de que Obama se inspire en la oratoria de otros presidentes que le han precedido aparece como algo positivo e incluso se menciona que transmite un mensaje renovado que ha tenido la fortuna de dar con un lema potente: Sí podemos (yes, we can) con el que ha tratado de inspirar e impulsar al electorado, ayudado por la gran la utilización de la red en estas elecciones.

Con Obama se cumple la idea del sueño americano de que cualquier persona puede llegar a convertirse en presidente de Estados Unidos, cualquier ciudadano, exceptuando, hasta la fecha, un ateo. Una persona no protestante, joven, mulata, con nombre musulmán, ha accedido a la presidencia con una campaña en la que sabido transmitir y difundir la idea de unidad y cambio al pueblo americano. En más de una ocasión, la prensa española nos ha recordado las palabras de Obama que hacen referencia a la excepcionalidad del caso estadounidense y a la realización del sueño americano, al hecho de que una historia como la suya sólo puede suceder en un lugar como Estados Unidos.

En definitiva, cabe destacar que el mensaje que prevalece en la prensa liberal española es de respeto y admiración hacia el presidente electo Barack H. Obama, haciéndose eco de un discurso poderoso que presenta al público lector a un hombre sensato, con juicio, que, aunque carezca de experiencia, sabe rodearse de un buen equipo para tratar de tomar las decisiones adecuadas. Obama aparece ante la opinión pública como un posible modelo a seguir en un momento crítico de la economía española y mundial.

${ }^{83}$ Extracto de la Conferencia de prensa de Chicago recogida en el artículo «Obama: Es hora de un nuevo amanecer». El País, 2-12-2008, p. 2. 